\title{
Superflat o el carácter híbrido de la cultura japonesa según Takashi Murakami
}

\author{
Ana TrujlLlo DenNis \\ Universidad Complutense, Facultad de Geografía e Historia \\ Departamento de Historia del Arte III \\ truj_den@hotmail.com
}

\begin{abstract}
RESUMEN
El presente artículo propone una mirada a los años iniciales de la carrera del artista japonés Takashi Murakami, hasta el año 2000 en el que definió un nuevo movimiento artístico, Superflat. En esta primera fase, anterior a su interpretación mercantilista del arte, vemos cómo el artista busca poner en evidencia el carácter híbrido de la cultura japonesa, reflejado entre otros aspectos en la pintura nihonga y en la cultura popular japonesa, dos elementos decisivos en la configuración del lenguaje artístico de Murakami.
\end{abstract}

Palabras clave: Takashi Murakami; identidad; hibridismo; nihonga; cultura popular.

\section{Superflat or the hybrid character of Japanese culture according to Takashi Murakami}

\begin{abstract}
This paper proposes an insight into the initial years in Takashi Murakami's career, up to the year 2000 when the artist defined a new art movement, named Superflat. In this initial stage, we see how the artist aims to reveal the hybrid character of Japanese contemporary culture, seen especially in nihonga painting and Japanese popular culture, two elements that had a definitive influence in the configuration of the artist's artistic language.
\end{abstract}

Key words: Takashi Murakami; identity; hybridism; nihonga; popular culture. 


\section{INTRODUCCIÓN}

Takashi Murakami ${ }^{1}$ (Tokio, 1962) es un artista extremadamente prolífico y polifacético. A través de su obra (teórica y práctica) el artista ha abordado múltiples aspectos de la cultura japonesa contemporánea. Su obra es un claro ejemplo del uso estratégico y la mercantilización de la identidad japonesa como objeto de deseo y de consumo en el mercado internacional y, más específicamente, en el occidental. En este artículo se pretende analizar un período concreto de su obra, el comprendido entre la década de 1980 y el año 2000, es decir, sus años de formación y el inicio de su práctica artística profesional hasta el momento en que definió un nuevo movimiento artístico que denominó Superflat y en el que adscribía su obra junto con la de numerosos jóvenes artistas japoneses del momento. En esta primera fase de su carrera vemos cómo la identidad japonesa ya era un aspecto fundamental de su producción. Podemos explicar esta fase inicial como un período de búsqueda de un lenguaje artístico adecuado para plasmar su visión crítica de la realidad japonesa del momento, especialmente su carácter híbrido. Este carácter híbrido se fundamenta en la fuerte influencia occidental, sobre todo norteamericana, que ha determinado la cultura japonesa desde el final de la Segunda Guerra Mundial. En la segunda mitad de la década de 1990 el artista consolidó un lenguaje heredero del Pop Art, que es el que le ha consagrado como artista y le ha dado fama. Sin embargo, antes de llegar a él Murakami osciló entre la pintura tradicional japonesa y una obra de corte conceptual.

Japón, a lo largo de su historia, ha estado expuesto a distintas oleadas de influencia extranjera, cuyo resultado en muchas ocasiones fue la adopción y adaptación a la idiosincrasia propia. Hasta finales del siglo XIX la fuente principal de influencia extranjera, y el gran referente en la cultura japonesa, fue China. A partir de finales del siglo XIX, China sería sustituido por Occidente y, especialmente a partir de la Segunda Guerra Mundial, Estados Unidos.

El proceso de modernización experimentado por Japón desde finales del siglo XIX ha sido descrito desde distintos sectores como "un proceso de apropiación, domesticación e indigenización". ${ }^{2}$ El resultado de este proceso es el marcado carácter híbrido de la cultura japonesa. Según Koichi Iwabuchi, desde Occidente, en numerosas ocasiones se ha difundido esta imagen, dotándola de un fuerte componente negativo: Japón como feroz imitador. Sin embargo, desde Japón, la capacidad de préstamo y asimilación de la cultura japonesa, más allá de la evidente articulación de un proceso de hibridación, ha sido empleada estratégicamente para representar lo que se define como un rasgo esencial de la identidad nacional de Japón, que lo distingue de cualquier otra nacionalidad: su capacidad de asimilar culturas foráneas sin perder su esen-

1 En este artículo se ha optado por emplear el nombre del artista japonés según el modo occidental (nombre seguido del apellido), y no el modo japonés (apellido seguido del nombre), ya que es así como es conocido internacionalmente. Este modo ha sido también empleado para los demás nombres japoneses contemporáneos que aparecen mencionados en este texto. Nombres pertenecientes a un período anterior al Meiji (1868-1912) se emplean de la forma tradicional. Todos los textos en inglés citados han sido traducidos por la autora. El texto original se ha incorporado en las notas a pie de página.

2 IWABUCHI, Koichi, Recentering Globalization. Popular Culture and Japanese Transnationalism, Durham y London, Duke University Press, 2002, p. 53. 
cia cultural/nacional. ${ }^{3}$ Este "hibridismo estratégico", tal como lo define este autor, ha sido un elemento recurrente en la historia reciente de Japón desde que, tras la derrota en la Segunda Guerra Mundial, el país experimentara un espectacular crecimiento económico que propiciara su contacto con otros países, y en especial, con Occidente.

El carácter híbrido de la cultura japonesa está muy presente en la obra de Takashi Murakami. Dos de los elementos que tuvieron una gran influencia en el período de formación y los primeros años como artista de Murakami son un claro ejemplo de cómo la cultura japonesa ha recibido una fuerte influencia extranjera que luego ha sido adaptada para crear un lenguaje propio: por un lado nihonga o pintura tradicional japonesa, y por otro, el lenguaje visual del manga y del anime, los cómics y dibujos animados japoneses. Ambos lenguajes, aunque aparentemente identificados como plenamente japoneses, como veremos, tienen en su origen un importante componente occidental. Además, en su formulación del movimiento Superflat, podemos ver un ejemplo del "hibridismo estratégico", según la definición de Koichi Iwabuchi.

\section{TAKASHI MURAKAMI Y LA ESCUELA DE PINTURA NIHONGA}

Takashi Murakami realizó sus estudios de Bellas Artes en la Universidad Nacional de Bellas Artes y Música de Tokio (Tôkyô Geijutsu Daigaku) ${ }^{4}$. Ésta es una de las universidades de mayor prestigio para el estudio de las Bellas Artes en Japón. En esta universidad Murakami realizó sus estudios de licenciatura, master y doctorado en la especialidad de pintura tradicional japonesa o nihonga. Inició sus estudios de licenciatura en el año 1980 y se doctoró en el año 1993. Es decir, durante más de 10 años se adentró en el conocimiento y perfeccionamiento de esta escuela pictórica y, sin embargo, tras doctorarse decidió abandonar la práctica de nihonga, de marcado carácter tradicional, e inclinarse hacia un arte de corte más vanguardista. Para encontrar una respuesta a este cambio debemos entender el origen y las implicaciones de la pintura nihonga.

Los orígenes de lo que se conoce como nihonga, o pintura tradicional japonesa, se remontan realmente a finales del siglo XIX cuando el país inició su proceso de modernización. En esos momentos la modernidad fue entendida en Japón como la adopción indiscriminada de los modos occidentales. Esta marea de occidentalización también afectó al mundo de la cultura y de las artes. ${ }^{5}$

En el campo de la pintura japonesa, a lo largo de los siglos se habían desarrollado distintas escuelas pictóricas que se transmitían de generación en generación, como las escuelas Kanô, Tosa o Ukiyo-e. Frente a estas escuelas autóctonas, por influencia

3 Ibid. p. 53.

4 Actualmente denominada Universidad de las Artes de Tokio.

5 Es en este momento cuando se introduce en la cultura japonesa el concepto de Bellas Artes, que como tal no había existido en Japón hasta ese momento, y por lo tanto hubo de fijarse un término para referirse a esta categoría que había sido importada desde Occidente. Así se acuñaron los términos bijutsu para referirse a las Bellas Artes, y geijutsu para referirse a otro tipo de artes. CONANT, Ellen P., Nihonga: Transcending the Past: Japanese-Style Painting, 1868-1968, catálogo de la exposición, (St. Louis, 1995), St. Louis, The Saint Luis Art Museum, y Tokyo, The Japan Foundation, 1995, p. 14. Ver también: MURAKAMI, Takashi, “A Theory of Japanese Super Flat Art”, en Super Flat, Tokyo, Madora Shupan, 2000, p. 15. 
extranjera, se empezó a practicar la pintura al óleo, copiando no sólo la técnica, sino también los formatos, los recursos expresivos y los modos de representación. ${ }^{6}$ Es en este contexto en el que surge nihonga (literalmente, pintura japonesa): como contraposición a la pintura de estilo occidental o yôga. Estas dos escuelas pictóricas enfrentaban no sólo dos técnicas distintas, sino también dos modos de ver y representar la realidad. En última instancia, eran una manifestación de lo que se vino a interpretar como el conflicto entre el idealismo de Asia Oriental y el racionalismo occidental. ${ }^{7}$

La consolidación de la pintura nihonga se debe a los esfuerzos de dos personas: Ernest F. Fenollosa (1853-1908) y Okakura Kakuzô (1862-1913) que buscaron crear una nueva escuela de pintura en la que se fundieran los elementos más significativos de la tradición pictórica autóctona y de la pintura occidental. Frente a la invasión del estilo occidental, Fenollosa y Okakura trataron de revitalizar el arte tradicional japonés y buscaron la consolidación de una forma de expresión autóctona, auténticamente japonesa y más acorde con los nuevos tiempos. ${ }^{8}$ Para ello realizaron un estudio profundo sobre los métodos de expresión del realismo óptico del arte europeo, el uso de la luz, el claroscuro y la representación tridimensional del espacio. ${ }^{9}$ Es decir, la renovación y consolidación de un lenguaje propiamente japonés vino determinada por una clara influencia occidental. ${ }^{10}$ La pintura nihonga, aunque marcada por la influencia occidental, mantenía su carácter japonés. Vemos reflejado aquí el discurso del "hibridismo estratégico" que defiende la capacidad de la cultura japonesa de asimilar influencias foráneas sin perder la esencia autóctona. ${ }^{11}$

Desde el período Meiji (1868-1912), y hasta el día de hoy, estas dos escuelas pictóricas han existido a la par, pero siempre independientes una de la otra: en exposiciones, concursos o en los programas académicos siempre se presentan por separado. ${ }^{12}$ En la actualidad la mayoría de las facultades de Bellas Artes de Japón tienen departamentos separados para nihonga y pintura al óleo, aunque realmente lo único que diferencia las dos corrientes pictóricas son los temas y los materiales empleados. ${ }^{13}$

6 En realidad, durante el período Edo (1603-1868) la pintura japonesa ya había estado expuesta con anterioridad a la influencia occidental, a través del contacto con los comerciantes holandeses que estaban asentados en la isla de Deshima en Nagasaki.

7 CROISSANT, Doris, "In Quest of the Real. Portrayal and Photography in Japanese Painting Theory", en CONANT, Ellen P. (ed.), Challenging past and present: the metamorphosis of nineteenth-century Japanese art, Honolulu, University of Hawai'i Press, 2006, p. 153.

8 CABAÑAS, Pilar, "Kokoro Nihonga. Pintura japonesa al estilo occidental”, Adamar, n 2, otoño, 2000, http://www.adamar.org/oldesign/num2/pag2 25.htm

9 CABAÑAS, Pilar, "Nihonga. Pintura japonesa al estilo tradicional", Contrastes, septiembre, 2005 , p. 42.

10 Esta nueva corriente pictórica se consolidó en la Escuela de Bellas Artes de Tokio (fundada en 1889 por Fenollosa y Okakura), y más tarde en el Instituto de Arte Japonés (Nipon Bijutsu-in, fundado en 1898).

11 Es interesante mencionar también cómo muchas de las escuelas pictóricas japonesas fundidas en la escuela nihonga habían recibido a su vez influencias extranjeras, especialmente de China.

12 La época de gran esplendor de esta corriente pictórica fue el período anterior a la Segunda Guerra Mundial. Hacia mediados del siglo XX surgió una nueva generación de artistas de la escuela nihonga que empezaron a introducir novedades en este estilo tan marcado por la tradición. YAGUCHI, Kunio, "The 1964/ Tokyo Olympics/And... A Turning Point in Japanese Art”, en 1964: A Turning Point in Japanese Art, catálogo de la exposición (Tokyo, 1996), Tokyo, Museum of Contemporary Art, 1996, p. 186.

13 Ibid., p. 186. 
La Escuela de Bellas Artes de Tokio fundada por Fenollosa y Okakura es en la actualidad la Tôkyô Geijutsu Daigaku, la universidad donde estudió Murakami. Su programa de estudios de nihonga se presenta como heredero de la filosofía original de esta institución, estableciendo como su misión la transmisión y el refinamiento de "las técnicas tradicionales y el espíritu del arte japonés" a través de la realización de obras de arte actuales. ${ }^{14}$ Es interesante resaltar cómo, a pesar de tratarse de un ejemplo del carácter híbrido de la cultura japonesa, sin embargo es ensalzada como representativa y continuadora de lo que se ha venido en llamar el "espíritu del arte japonés". Ya desde sus orígenes, la pintura nihonga estuvo estrechamente vinculada con el concepto de identidad nacional de Japón. Para Okakura Kakuzô el arte, y en especial la pintura nihonga, era, no sólo expresión de la identidad nacional, sino también un instrumento para su consolidación. La nueva escuela de pintura japonesa debía aglutinar en Japón un sentimiento patriótico hacia la cultura autóctona e inspirar admiración en el extranjero. ${ }^{15}$ Este vínculo entre nihonga e identidad nacional se mantuvo desde entonces. Según el propio Murakami, la pintura nihonga a partir de la derrota en la Segunda Guerra Mundial había contribuido a consolidar en el imaginario colectivo japonés una representación visual del sentimiento de identidad compartido del pueblo japonés, sentimiento que tras la derrota en la contienda mundial había costado mucho reconstruir. ${ }^{16}$

Debemos preguntarnos la razón por la cual Takashi Murakami eligió el itinerario de la pintura nihonga al ingresar en la universidad. En un principio Murakami quería convertirse en dibujante de anime. Este artista pertenece a la generación de japoneses que se crió en los años 60 y 70 del siglo pasado, cuando Japón empezó a experimentar su crecimiento económico tras los años de la posguerra. La generación de los japoneses que se criaron en esta época fue la que comenzó a disfrutar de la televisión y de la industria del entretenimiento, a través de manifestaciones culturales como el manga (cómics), el anime (dibujos animados) o los videojuegos.

Murakami ingresó en el departamento de nihonga con la intención de, al abrigo de su especialización en este departamento, aprender recursos técnicos que le sirvieran para la creación de fondos para anime. De hecho, compaginó sus primeros años de estudios universitarios con clases de animación en una academia. ${ }^{17}$ Quizá Murakami considerara que la completa formación técnica que ofrecía el departamento de $n i$ honga le ofrecería los recursos adecuados para crear fondos de animación como los que el artista admiraba de producciones como las del director Hayao Miyazaki. Paul

14 "In addition to promoting creativity in modern painting, education and research within the Painting's Department Japanese Painting Course also focuses on handing down and refining the traditional techniques and spirit of Japanese art". En: http://www.geidai.ac.jp/english/art/painting.html

15 WESTON, Victoria, Japanese Painting and National Identity, Ann Arbor, The University of Michigan, 2004, p. 2-3.

16 MATSUI, Midori, "Toward a Definition of Tokyo Pop: The Classical Transgressions of Takashi Murakami”, en CRUZ, Amada, FRIIS-HANSEN, Dana y MATSUI, Midori (eds.), Takashi Murakami: The Meaning of the Nonsense of the Meaning, catálogo de la exposición (Annandale-on-Hudson, NY, 1999), New York, Harry N. Abrams, Inc., 1999.

17 SCHIMMEL, Paul, "Making Murakami”, en SHIMMEL, Paul (org.), @Murakami, catálogo de la exposición (Los Angeles, 2007), Los Angeles, Museum of Contemporary Art y New York, Rizzoli International Publications Inc., 2007, p. 57. 
Shimmel apunta otra posible razón: en el momento en el que el artista ingresó en la Universidad Nacional de Bellas Artes y Música de Tokio era más fácil entrar en el departamento de nihonga que en el de pintura al óleo, que por entonces era considerado como un departamento muy elitista. ${ }^{18}$ El departamento de nihonga se había convertido en un departamento marginal, que simplemente formaba sus estudiantes como artesanos, y en el que la discusión intelectual sobre el arte era desdeñada. ${ }^{19}$

Finalmente, Murakami dejaría de lado tanto su idea inicial de dedicarse a la industria de la animación como su especialización en pintura nihonga. ${ }^{20}$ Sin embargo, ambos mundos han seguido influyendo en su obra artística hasta la actualidad. Según Paul Shimmel, de su estudio de la animación aprendió por un lado la complejidad de la creación de personajes, fondos y composiciones dinámicas, y por otro lado, la utilidad de trabajar en equipo. De sus estudios de nihonga aprendió distintas técnicas artísticas en el uso de colores y materiales, que luego aplicaría a su obra. ${ }^{21}$

\section{UNA MIRADA HACIA LA CULTURA POPULAR JAPONESA: OTAKU Y KAWAII}

Ya antes de finalizar sus estudios de doctorado Murakami había decidido dedicarse a la práctica artística contemporánea. Al igual que muchos de sus compañeros de universidad, Murakami estaba muy decepcionado con la formación que estaba recibiendo, que le parecía bastante anticuada y poco estimulante. Ante la ausencia de una dirección clara y de un discurso crítico relevante en el arte contemporáneo japonés, muchos de estos jóvenes artistas de la generación de Murakami buscaron inspiración en el mundo de la cultura popular y la subcultura, y en la estética del manga y del anime.

A principios de la década de los 90 Murakami empieza a explorar el mundo de la cultura popular japonesa. Si en la escuela de nihonga vemos un claro ejemplo de ese carácter híbrido de lo japonés, en la cultura popular, especialmente en el manga y el anime, vemos claramente otro. El cómic o manga moderno surge en Japón a finales del siglo XIX, cuando aparecen las primeras tiras cómicas ligadas a los primeros periódicos publicados en Japón, de clara influencia occidental. Quizá para contrarrestar este elemento foráneo en uno de los emblemas de la cultura popular japonesa actual, siempre que se analizan los orígenes del manga estos se remontan a los rollos pictóricos (emaki) del siglo XII, buscando demostrar que ya existía una antigua tradición en el arte japonés, anterior a la llegada de los occidentales, en la que se valoraba el

18 Ibid., p. 57.

19 MATSUI, Midori, “Conversation Days: New Art between 1991 and 1995”, en SINGERMAN, Howard (ed.), Public Offerings, catálogo de la exposición (Los Angeles, 2001), New York, Thames and Hudson, 2001, p. 244.

20 Aunque con posterioridad ha producido distintos trabajos de animación.

21 SCHIMMEL, Paul (2007), op. cit., p. 58. 
dibujo vinculado a la narración de historias. Además, también se hace constar el origen del término manga, que fue acuñado por Hokusai a principios del siglo XIX. ${ }^{22}$

Tras la Segunda Guerra Mundial la industria del manga y del anime se consolidó. En este proceso es necesario mencionar la influencia de autores americanos como Disney o los hermanos Fleischer. La industria del manga, el anime y otras formas de entretenimiento como los videojuegos, fueron poco a poco, ampliando su público y su temática. La generación de Murakami experimentó directamente el boom de la nueva industria del entretenimiento. ${ }^{23}$

A principios de los años 90, tras descartar la pintura nihonga, Murakami se adentra en la práctica de arte vanguardista con la intención de realizar una crítica de la sociedad contemporánea japonesa que le llevará a buscar inspiración en el mundo de la cultura popular japonesa contemporánea. Sus primeras obras se encuadran dentro de la línea del "apropiacionismo". En ellas hacía uso de productos de consumo para desmitificarlos a través de una modificación cargada de sarcasmo y de crítica a la sociedad japonesa contemporánea y su relación de dependencia con los Estados Unidos. ${ }^{24}$ A este período pertenecen obras como Polyrhythm (1991), en las que emplea soldados de juguete fabricados por Tamiya, una reconocida empresa japonesa fabricante de figuras y maquetas, y que representaban soldados norteamericanos de la Segunda Guerra Mundial. En otro grupo de obras se apropia del logotipo y de la identidad como marca de Tamiya, sustituyendo el nombre de la empresa por el suyo propio (Signboard Takashi, 1992). En Randoseru (1991) se apropió de las típicas mochilas utilizadas por los escolares japoneses empleando pieles de diversos animales, cuyo uso en algunos casos estaba prohibido. ${ }^{25}$

En el análisis realizado por el artista del panorama contemporáneo japonés destaca la interpretación que hace de dos conceptos recurrentes: otaku y kawaii. Por un lado otaku, el movimiento de los fans del anime y del manga, de un carácter marcadamente masculino, y por el otro kawaii, el mundo de la "monada" (en inglés cuteness). Murakami propone que los conceptos de kawaii y otaku surgieron del trauma experimentado por la sociedad japonesa tras la aniquilación producida por el bombardeo sobre Hiroshima y Nagasaki. ${ }^{26}$ Son también resultado de la humillación, impotencia

22 Sin embargo, hay que mencionar que el manga de Hokusai era un conjunto de dibujos publicados por el artista que debían servir de modelo a sus seguidores y carecía del componente narrativo.

23 Durante los años 30 y hasta el estallido de la Segunda Guerra Mundial la industria del manga experimentó un desarrollo espectacular. Durante la guerra, empezó a ser utilizado como propaganda. El poder político echó manó del cómic y transformó un pasatiempo cotidiano en un medio de propaganda bélica, centrado en la mofa y la demonización de los países enemigos (al igual que había ocurrido en el bando contrario). SANTIAGO, José Andrés, "Japón: contando historias gráficas, del mundo flotante del Ukiyo-e al consumo del manga", en SOLER, Ana y CASTRO, Kako (coords.), Impresión Piezoeléctrica. La estampa inyectada: algunas reflexiones en torno a la gráfica digital, Pontevedra, dx5/Universidad de Vigo, 2006, pp. 142-165.

24 YOSHITAKE, Mika, "The Meaning of the Nonsense of Excess", en SHIMMEL, Paul (org.) (2007), op. cit., p. 113.

25 El diseño original de estas mochilas tenía un origen militar y, con su obra, Murakami estaba haciendo por un lado una crítica al pasado militar de Japón, y por otro, al consumismo desaforado que había caracterizado a la sociedad japonesa desde los años 80 del siglo pasado.

26 MURAKAMI, Takashi, "Superflat Trilogy. Greetings you are alive", en MURAKAMI, Takashi (ed.), Little Boy. The Arts of Japan's Exploding Subculture, catálogo de la exposición (Nueva York, 2005), New Haven y London, Yale University Press, New York, Japan Society, 2005, p. 153. 
y subsiguiente infantilización que, según el artista, produjo en la sociedad japonesa la ocupación e imposición cultural norteamericana. ${ }^{27}$

Como resultado de este análisis, a finales de la década de los 90 Murakami comenzó a realizar obras que tomaban prestado del anime y del manga su expresión formal, y que aludían a estos conceptos. A finales de los 90 el artista realizó una serie de esculturas que se inspiraban en las pequeñas figuritas que representan a los personajes favoritos de los otaku, que muchas veces tienen una clara connotación sexual, y que son objeto de sus fantasías. Sin embargo, las obras de Murakami representan personajes diseñados por él mismo a un tamaño mucho mayor. A este grupo de obras pertenecen, por ejemplo, Miss Ko (1997), Hiropon (1997), My Lonsesome Cowboy (1998) y Second Mission Project $K^{2}{ }^{2}$ (1998).

Es en este período cuando surge el personaje DOB, que se encuadra en la otra línea de trabajo de Murakami, la vinculada con el concepto de kawaii: objetos amables, simpáticos, "monos". En muchas obras de Murakami encontramos presente esta imagen de lo kawaii, como sus flores y champiñones, o las criaturas Kaikai y Kiki. Pero quizá el personaje más relevante sea Mr. DOB, personaje que es una combinación de Doraemon, el famoso gato-robot, y Sonic, el erizo mascota de Sega, con algunos elementos que recuerdan al ratón Mickey. ${ }^{28} \mathrm{DOB}$, con sus múltiples transformaciones, se convirtió en el tema más recurrente de la obra de Murakami en la década de 2000, y ha sido empleado en la estrategia mercantil adoptada por el artista desde entonces.

\section{EL MOVIMIENTO SUPERFLAT}

En el año 2000, tras esta exploración inicial de la cultura contemporánea japonesa, Murakami definió el movimiento Superflat, a través de un manifiesto que fue publicado en el catálogo de la exposición, de igual nombre, que se inauguró en primer lugar en la Parco Gallery de Tokio, y que fue mostrada posteriormente en Estados Unidos, en el Los Angeles Museum of Contemporary Art (MOCA).$^{29}$ Esta exposición colectiva fue comisariada por el propio artista, y en ella Murakami incluyó obra de distintos artistas y diseñadores japoneses que, desde la década de 1990, trabajaban en la misma línea marcada por el manifiesto, buscando inspiración en el mundo de la cultura popular y de consumo. En el catálogo, además del manifiesto y de un texto en el que el artista explicaba su teoría sobre Superflat, se incluían numerosas reproducciones con las que el artista esperaba transmitir visualmente su teoría. Entre los artistas incluidos en la exposición destacan: Yoshitomo Nara, Chiho Aoshima, Aya Takano, Mr., y el colectivo groovisions.

Murakami, tal y como explicaba en el catálogo, percibía una tendencia a la bidimensionalidad en Japón: en la sociedad, la cultura, el arte o las costumbres. Esta ten-

\footnotetext{
27 HEBDIGE, Dick, "Flat Boy vs. Skinny: Takashi Murakami and the Battle of 'Japan'”, en SHIMMEL, Paul (org.) (2007), op. cit., p. 41.

28 SHIMMEL, Paul, (2007), op. cit., p. 65-67.

29 Tras su exhibición en Los Ángeles, la exposición viajó al Walker Art Center, Minneapolis y la Henry Art Gallery, Seattle.
} 
dencia a lo bidimensional no era nueva, sino que se remontaba a períodos anteriores de la historia de Japón, en concreto al período Edo (1603-1868). En el arranque del siglo XXI, Murakami veía claramente reflejada esta sensibilidad en el mundo de los videojuegos y el anime. ${ }^{30}$ Según queda reflejado en este breve manifiesto, a través del catálogo (y de la exposición) Murakami trataba de demostrar que la sensibilidad de lo superflat era un concepto original japonés que había sido transformado por la influencia occidental sobre Japón, y por lo tanto, era un producto híbrido de la cultura japonesa: "lo 'super flat' ${ }^{31}$, la sensibilidad que ha contribuido y que continúa contribuyendo a la construcción de la cultura japonesa, como visión del mundo, (...) es un concepto original que conecta el pasado con el presente y el futuro. Durante el período contemporáneo, a medida que Japón ha sido occidentalizado, ¿cómo se ha metamorfoseado esta sensibilidad? Si podemos comprender esto de una forma clara, entonces nuestra posición actual se verá con mayor claridad. (...) Lo 'super flat' es un concepto original de un Japón que ha sido completamente occidentalizado". ${ }^{32}$ Lo 'super flat' es, por tanto, un concepto original japonés que ha sufrido una transformación como resultado de la influencia occidental, pero que sigue siendo auténticamente japonés. Por ello, podemos interpretar la definición de este concepto como un ejemplo del "hibridismo estratégico" definido por Koichi Iwabuchi, y mencionado al comienzo de este artículo.

El término superflat sugiere un concepto visual: una alusión a la planitud propia de las obras de Murakami y de otros artistas vinculados a su estela. Esta planitud formal vincula al movimiento Superflat con las manifestaciones culturales que se consolidaron en Japón desde los años 60, vinculadas a los gráficos por ordenador. Sin embargo, Murakami va más allá en el fundamento histórico de Superflat. El artista se remonta al período Edo (1603-1868). Formalmente, Murakami parte de las teorías del historiador del arte japonés Nobuo Tsuji, que defiende que en el período Edo existió una serie de artistas que, en sus composiciones, tendieron a negar la profundidad espacial y crearon imágenes "superficiales", que hacían al espectador consciente de la planitud de la superficie pictórica. El historiador denominaba a estos artistas "excéntricos". Según Murakami, el vínculo de estos artistas con el presente es la obra del gran creador de anime, Yoshinori Kanada y su escuela. ${ }^{33}$ En el catálogo acompañante de la exposición Superflat, editado por el propio artista, se presentan imágenes de algunas

30 MURAKAMI, Takashi, “Super Flat Manifesto”, en MURAKAMI, Takashi (2000), op. cit., p. 5.

31 Aunque en origen, el término inglés empleado estaba formado por dos palabras, "super flat", tras la llegada de la exposición a Estados Unidos se juntaron los dos términos, y se consolidó el término 'Superflat'. En esta comunicación, para homogeneizar y evitar la confusión, se emplea el término original, "super flat" tan sólo cuando se trate de citas tomadas del catálogo de dicha exposición. En todos los demás casos, se empleará el término "superflat".

32 "'super flatness', the sensibility that has contributed to and continues to contribute to the construction of Japanese culture, as a worldview, (...) is an original concept that links the past with the present and the future. During the modern period, as Japan has been Westernized, how has this "super flat" sensibility metamorphosed? If that can be grasped clearly, then our stance today will come into focus. (...) 'Super flatness' is an original concept of Japanese who have been completely Westernized. (...). En: MURAKAMI, Takashi (2000), op. cit., p. 5.

33 MURAKAMI, Takashi, “A Theory of Super Flat Japanese Art”, en MURAKAMI, Takashi (2000), op. cit., p. 15. 
películas de Kanada junto con obras de artistas del período Edo, como Katsushika Hokusai o Kanô Sansetsu.

Superflat remitía también a una idea de nivelación entre alta y baja cultura. Según Murakami, las artes consideradas como populares en Japón no habían sido desdeñadas como menores. Sin embargo, durante unos años tras la Segunda Guerra Mundial, el arte japonés se movió de acuerdo a ciertas imposiciones occidentales que claramente distinguían entre alta y baja cultura. A partir de la década de los 90 habían surgido nuevas directrices liberando a la cultura japonesa de estas distinciones, por lo que estaban triunfando prácticas culturales que en Occidente se etiquetaban como subcultura. ${ }^{34}$

Debemos fijarnos también en el propio nombre que Murakami dio a este movimiento y a la exposición que lo definía. El artista podía haber escogido algún término japonés que aludiera a la idea de planitud. Sin embargo, optó por un anglicismo: "super flat". El idioma japonés está plagado de palabras extranjeras, en su mayoría tomadas del inglés. En Japón el mundo de la publicidad, la televisión, la moda, la música, etc. están invadidos por términos importados que muchas veces son simplemente escogidos por su sonoridad; estos términos prestados son siempre adaptados a la pronunciación fonética del japonés. Además, existe un silabario específico para escribir estas palabras, el katakana. Por ello, estos términos se reconocen como extranjeros no sólo sonoramente sino también visualmente. Así, el término "super flat", en japonés se convierte en "suppaa furatto" y se escribe en katakana. De este modo, el propio término adoptado del inglés contribuía a consolidar esta idea de que el concepto de superflat, aunque originalmente japonés, había sido transformado por la influencia occidental.

\section{CONCLUSIÓN}

Vemos por lo tanto cómo en los inicios de su carrera artística, Takashi Murakami estaba interesado fundamentalmente en analizar y poner de relieve las contradicciones de la cultura japonesa del momento, especialmente en su dependencia de la cultura norteamericana y, por extensión, occidental. En esta primera etapa aún no vemos claramente identificado el afán mercantilista, que ha caracterizado su obra ya bien entrada la década de 2000. En numerosas ocasiones el artista ha afirmado que su único objetivo ha sido vivir del arte. En el año 2005, en una entrevista afirmaba: "Lo que he hecho hasta ahora ha sido ganarme la vida. He sido muy estratégico respecto al tipo de cuadros que debía realizar con ese propósito. Incluso esta entrevista podría ser buena para el negocio". ${ }^{35}$ Sin embargo, a pesar de estas palabras, su obra de la

34 SAWARAGI, Noi, "On the Battlefield of "Superflat", en MURAKAMI, Takashi (ed.), (2005), op. cit. p. 206, nota 1 .

35 "What I have done so far was to make a living. And I was highly strategic about what kind of paintings I should make for that purpose. Even this interview could be good for business", en WAKASA, Mako, Takashi Murakami, (entrevista realizada el 24 de febrero de 2004). Journal of Contemporary Art. http://jca-online. com/murakami.html. 
década de 1990 parece estar más centrada en la búsqueda de un lenguaje propio que le sirviera para representar la compleja realidad de la cultura japonesa.

Para terminar, es necesario decir que muchas de las ideas que Takashi Murakami recogió en su formulación del movimiento Superflat, estaban en el aire y habían sido identificadas ya desde principios de la década de 1990 por numerosos especialistas y críticos, no sólo japoneses sino también extranjeros. Sirvan de ejemplo las palabras escritas por Ian Buruma en el catálogo de la exposición A Cabinet of Signs. Contemporary Art from Post-Modern Japan organizada en el año 1991 por la Tate Gallery Liverpool, y en el que se apuntan muchas de las cuestiones enunciadas por Murakami en su proyecto Superflat: "El alto grado de seriedad y didacticismo del período Meiji han desaparecido (excepto en la pintura al óleo). La alta cultura ha sido prácticamente absorbida en su totalidad por el volumen y la masa del mundo del entretenimiento popular y de la publicidad. La cultura de Tokio, al igual que la cultura de Edo y de Osaka hace unos siglos, está regida por un público cada día más afluente, obsesionado con el gusto, la moda, el placer, en definitiva, con la superficialidad de las cosas más que por las profundidades ocultas. Es un mundo (...) ideal para el postmodernismo, un mundo en el que una galería de arte moderno y un showroom de Armani o Yohji Yamamoto no se distinguen entre sí, un mundo de estilos, clásico o moderno, que se escogen, se toman prestados y se desechan con igual facilidad, un mundo del pastiche, la parodia y el kitch". ${ }^{36}$

En definitiva, un mundo similar al recreado por Takashi Murakami.

\footnotetext{
36 "The high seriousness and didacticism of the Meiji Period have all but vanished (except in oil painting). High culture has been largely subsumed by the sheer volume and mass of popular entertainment and publicity. Tokyo culture, like that of Edo or Osaka some centuries ago, is driven by a public growing richer by the day, obsessed with taste, fashion, pleasure, in short, by the surface of things more than by the hidden depths, by what the artists of Edo called the floating world. It is a world, (...) ideally suited to postmodernism, a world where a modern art gallery and an Arman or Yohji Yamamoto showroom are indistinguishable, a world of styles, classical or modern, to be picked up, borrowed and discarded with equal ease, a world of pastiche, parody and kitch". BURUMA, Ian, "Japanese Avant Garde" en A Cabinet of Signs. Contemporary Art from Post-Modern Japan, catálogo de exposición (Liverpool, 1991), Liverpool, Tate Gallery, p. 17.
} 